\title{
Acute predator stress impairs the consolidation and retrieval of hippocampus-dependent memory in male and female rats
}

\author{
Collin R. Park, ${ }^{1,2}$ Phillip R. Zoladz, ${ }^{1,2}$ Cheryl D. Conrad, ${ }^{3}$ Monika Fleshner, ${ }^{4}$ \\ and David M. Diamond ${ }^{1,2,5,6}$ \\ ${ }^{1}$ Medical Research Service, VA Hospital, Tampa, Florida 33612, USA; ${ }^{2}$ Department of Psychology, University of South Florida, \\ Tampa, Florida 33620, USA; ${ }^{3}$ Department of Psychology, Arizona State University, Tempe, Arizona 85287-1104, USA; \\ ${ }^{4}$ Center for Neuroscience and Department of Integrative Physiology, University of Colorado, Boulder, Colorado 80309, USA; \\ ${ }^{5}$ Departments of Molecular Pharmacology and Physiology, University of South Florida, Tampa, Florida 33620, USA
}

\begin{abstract}
We have studied the effects of an acute predator stress experience on spatial learning and memory in adult male and female Sprague-Dawley rats. All rats were trained to learn the location of a hidden escape platform in the radial-arm water maze (RAWM), a hippocampus-dependent spatial memory task. In the control (non-stress) condition, female rats were superior to the males in the accuracy and consistency of their spatial memory performance tested over multiple days of training. In the stress condition, rats were exposed to the cat for 30 min immediately before or after learning, or before the 24-h memory test. Predator stress dramatically increased corticosterone levels in males and females, with females exhibiting greater baseline and stress-evoked responses than males. Despite these sex differences in the overall magnitudes of corticosterone levels, there were significant sex-independent correlations involving basal and stress-evoked corticosterone levels, and memory performance. Most importantly, predator stress impaired short-term memory, as well as processes involved in memory consolidation and retrieval, in male and female rats. Overall, we have found that an intense, ethologically relevant stressor produced a largely equivalent impairment of memory in male and female rats, and sex-independent corticosterone-memory correlations. These findings may provide insight into commonalities in how traumatic stress affects the brain and memory in men and women.
\end{abstract}

Over a century of behavioral research has revealed a powerful influence of stress on learning and memory (James, 1890; Yerkes and Dodson 1908; Hebb 1955; McGaugh 2000). The literature in this area lacks consistency, however, with studies reporting that stress can enhance, impair, or have no effect on learning and memory (for reviews, see Conrad 2005; Diamond 2005; Lupien et al. 2005; Diamond et al. 2007). An added level of complexity in the stress-memory literature involves the influence of gender on stress-memory interactions (Shors 1998; Wolf et al. 2001; Wolf 2003; Cahill et al. 2004; Cahill 2006). Some research has indicated that stress can impair memory in men but not women (Wolf et al. 2001), but other work has shown that stress can enhance memory in women (Andreano and Cahill 2006). Stress has also been shown to produce opposite effects on the development of conditioned responses in classical conditioning in men and women. However, in contrast to the studies mentioned above, Jackson et al. (2005) reported that stress produced an enhancement of fear conditioning in men and an impairment in women. Finally, other work has demonstrated that stress or cortisol administration can impair memory in both men and women (Kirschbaum et al. 1996; de Quervain et al. 2000; Wolf et al. 2004).

Studies investigating sex differences in stress-memory interactions in rodents have also produced inconsistent findings. Acute stress has been shown to impair spatial memory in male rats (Diamond et al. 1996, 1999; 2006; Conrad et al. 2004; Sandi

\footnotetext{
${ }^{6}$ Corresponding author.
}

E-mail ddiamond@mail.usf.edu; fax (813) 974-4617.

Article is online at http://www.learnmem.org/cgi/doi/10.1101//m.721108. et al. 2005) and to enhance spatial memory in female rats (Conrad et al. 2004). One explanation for this inconsistency is based on the suggestion by Korol and colleagues that at different phases of the estrus cycle there is a biasing of female rats toward dominance by hippocampal versus non-hippocampal (striatal) functioning in spatial learning tasks (Korol 2004; Korol et al. 2004; Zurkovsky et al. 2007). Female rats may have a differential reliance on hippocampal (spatial) versus non-hippocampal (response) strategies depending on their phase of estrus during behavioral testing, which may then interact with the differential susceptibility of hippocampal and non-hippocampal memory systems to stress (Kim et al. 2001, 2005; White and Salinas 2003; Kim and Jung 2006). It is also possible that the basis of the inconsistent findings in sex differences in rodents is the differential influence of gonadal hormones on the hippocampus of males versus females (Korol 2004; Korol et al. 2004; Zurkovsky et al. 2007), which may interact with the stressfulness of the learning situation (Beiko et al. 2004; Rubinow et al. 2004). Finally, the characteristics of the training conditions, such as whether animals are given classical, instrumental, or spatial training, can influence the expression of sex differences in performance (Shors and Dryver 1992; Shors et al. 1992; Servatius and Shors 1994; Shors 1998, 2001; Wood and Shors 1998; Wood et al. 1998; Conrad et al. 2004). Thus, there appears to be an influence of sex in the stress-induced modulation of memory in rodents and people, but many factors interact to influence performance (Packard 1998; Sauro et al. 2003; Shors 2005).

A different perspective on gender-related stress effects on memory is in the area of psychopathology produced by traumatic experiences. Exposure to extremely stressful, horrific, and life- 
threatening experiences such as motor vehicle accidents, terrorist acts, natural disasters, rape, and wartime combat produces cognitive responses that are qualitatively similar in men and women. That is, both men and women typically generate powerful memories of traumatic experiences, which can then foster the development of anxiety and mood disorders, such as posttraumatic stress disorder (PTSD) and major depressive disorder (MDD) (Bower and Sivers 1998; Dunmore et al. 1999; Lanius et al. 2004; Berntsen and Rubin 2006). Although women appear to be at a greater risk than men for developing stress-induced psychiatric disorders (Breslau et al. 1997; Foa and Street 2001; Fullerton et al. 2001; Nemeroff et al. 2006), men and women exhibit responses in common, including the formation of strong and intrusive memories of the traumatic experience, which can haunt them later in life (McFarlane et al. 1993; Gilbertson et al. 2001; Bremner 2003; Ohtani et al. 2004; Rubin et al. 2004; Michael et al. 2006).

One area of animal research that may potentially provide insight into commonalities in how males and females respond to trauma has been in studies on how rats respond to a predator. For example, Blanchard et al. (1991, 1992) demonstrated that male and female rats both generated $22-\mathrm{kHz}$ vocalizations in response to predator exposure when the rats were in groups, and both suppressed vocalizations when they faced the cat alone. Other work has shown that both males and females exhibit a strong and equivalent increase in defensive behaviors in the presence of predator odor (Falconer and Galea 2003). In memory-related work, Hubbard et al. (2004) examined learned avoidance by male and female rats of a context that contained predator (cat) odor. These investigators found that males and females developed similar levels of conditioning and subsequent avoidance (memory) of the place that contained the cat odor. These and related studies (Adamec et al. 1998, 2004; Park et al. 2001; Barros and Tomaz 2002; Adamec 2003; Campbell et al. 2003; Mechiel and De Boer 2003; Mazor et al. 2007) support the idea that the use of a strong ethologically relevant stressor provides insight into commonalities in how traumatic stress affects memory in males and females.

The purpose of the present set of experiments was to address the issues described above by examining the effects of an intense, ethologically relevant stressful experience (predator exposure) on spatial learning and memory in male and female rats. Prior work from our laboratory has shown that acute predator stress impairs spatial memory in male rats trained in the radial-arm water maze (RAWM) (Diamond et al. 1996, 1999, 2006; Woodson et al. 2003; Sandi et al. 2005; Park et al. 2006), a hippocampus-dependent spatial memory task (Diamond et al. 1999). It was important to determine whether the effects of predator stress on spatial memory found in male rats can be extended to female rats. Therefore, in the current series of experiments, we have provided a comparative analysis of the effects of acute predator stress on memory consolidation and retrieval processes in male and female rats.

\section{Results}

The following sections describe findings from four experiments that examined the effects of acute predator exposure on serum corticosterone (CORT) levels and memory when the stress was administered before or after water maze training or before a $24-\mathrm{h}$ memory retrieval test. The sequence and timing of the events in each experiment is illustrated in Figure 1.

\section{Effects of post-training stress on short-term memory (multi-day maze training)}

In experiment 1, 11 male and 15 female rats were first welltrained, and then they were all given predator stress during the

\section{Timelines and Procedures}

Experiment 1: Post-Training Stress (Multi-Day Training/Testing)

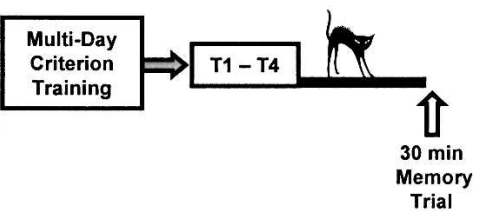

Experiment 2: Post-Training Stress (Single-Day of Training/Testing)


Experiment 4: Pre-Retrieval Stress (2-Day Training/Testing)

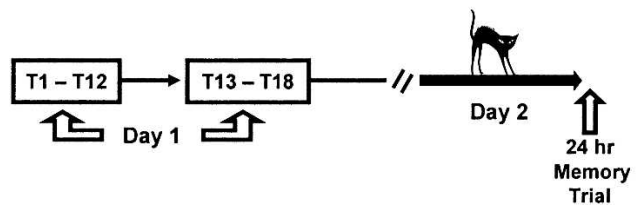

Figure 1. Timeline and procedures in the four experiments. In all experiments, the duration of the cat exposure period was $30 \mathrm{~min}$, which is illustrated here by the cat icon and the thick line. In experiment 1 , there were two multi-day components. First, all rats were given extensive preliminary training without predator stress until they reached the memory performance criterion (see multi-day criterion training). Second, after a rat reached the performance criterion, it was given six additional days of training, all of which included stress testing. On each of the stress days, cat exposure (predator stress) occurred during the 30-min period after the completion of the four acquisition trials (T1-T4) and before the 30 min memory test trial. The T1-T4 followed by cat exposure component of the diagram was repeated on six consecutive days, with the rats learning a new platform location on each day of training. In experiment 2 , naive rats were given only $1 \mathrm{~d}$ of water maze training and memory testing. On this day, they were given 12 training trials (T1-12) and then $30 \mathrm{~min}$ of predator stress or home cage (no stress), followed immediately by the memory test trial. In experiments 3 and 4, naïve rats were given a total of $2 \mathrm{~d}$ of training and memory testing. On day 1 , they were all given training, composed of 12 trials followed $1 \mathrm{~h}$ later by six more trials. One day later, all rats were given a 24-h memory test trial. In experiment 3, the rats were given $30 \mathrm{~min}$ of predator stress or home cage before training on day 1 . In experiment 4, the rats were given $30 \mathrm{~min}$ of predator stress or home cage immediately before the $24-\mathrm{h}$ memory test trial.

30-min period between the acquisition and memory test phases on six consecutive days of training (see timeline for experiment 1, Fig. 1). Therefore, data analysis in experiment 1 focused on two dependent variables: (1) the number of days required for males and females to reach the performance criterion (no more than one memory error in three consecutive days of non-stress training - see multi-day water maze training methods); and (2) postcriterion performance on the memory test trial under acute stress conditions.

As Figure 2 (left side) illustrates, females required 10.2 $( \pm 0.7)$ days of training, compared with males, which required 

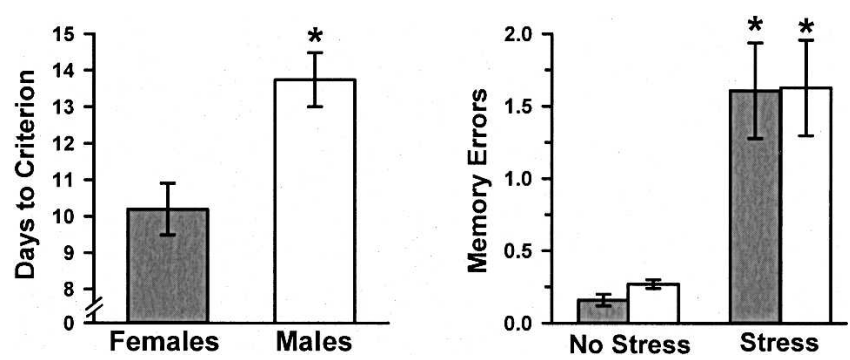

Figure 2. The left side illustrates the finding that females exhibited accurate within-day memory, reaching the memory performance criterion (see Materials and Methods, experiment 1) in significantly fewer days of training than the males. The right side illustrates that males and females were adversely affected equivalently by cat exposure. Both males and females exhibited a significant increase in errors on days they were exposed to the cat compared with the days in which they reached the performance criterion. Shaded bars in both graphs illustrate means $\left( \pm\right.$ SEM) for the female group. ${ }^{*} P<0.05$ compared with unstressed male and female controls (Holm-Sidak post-hoc comparisons).

$13.7( \pm 0.7)$ days of training, to reach the performance criterion $(P<0.05 ; t$-test). Thus, the group of male rats required 3.5 more days of training to reach the same level of accuracy of within-day memory as the group of female rats.

Memory performance during the $3 \mathrm{~d}$ of precriterion training was nearly perfect for males and females. That is, females committed only $0.16( \pm 0.04)$ errors and males committed 0.27 $( \pm 0.04)$ errors during the $3 \mathrm{~d}$ in which they reached the criterion. When the females were exposed to the predator, they committed $1.61( \pm 0.36)$ memory errors and the males committed 1.63 $( \pm 0.33)$ memory errors (Fig. 2, right). There was a significant effect of stress $\left(F_{(1,24)}=20.8, P<0.001\right)$, but neither a significant effect of sex nor a significant sex $\times$ stress interaction (all $P$ s $>0.05)$. Therefore, predator stress occurring during the 30-min phase between the learning and memory test phases in welltrained rats produced a significant and equivalent impairment of memory performance in males and females.

\section{Serum CORT levels}

Figure 3 shows serum CORT levels from the 11 male and 15 female rats trained in the water maze in experiment 1 . The first blood samples were obtained immediately after the last time the rats were exposed to the cat and given their final memory test trial. The second blood sample (baseline) was obtained $1 \mathrm{wk}$ later from rats within 2 min of their being removed from their home cages. In the across-group analyses (top graph), there were significant effects of $\operatorname{sex}\left(F_{(1,24)}=21.1, P<0.001\right)$, stress $\left(F_{(1,24)}=81.2, P<0.001\right)$, and a significant sex $\times$ stress interaction $(P<0.05)$. Post-hoc Holm-Sidak tests revealed that predator exposure increased CORT levels in males and females and that both baseline and stress-evoked CORT levels were significantly greater in the females than in males (all $P \mathrm{~s}<0.05$ ).

Additional analyses focused on potential correlations between CORT levels (baseline and stress) and water maze performance (memory errors and "day to criterion" [DTC]) separately for males and females, as well as for all rats, without regard for sex. There were no significant correlations between CORT (either baseline or stress levels) and water maze memory errors for males or females or for all rats combined (all $P s>0.05$ ). There was also no significant correlation between baseline and stress-evoked CORT levels when the analysis was restricted to either males or females, alone. We did find a significant positive correlation between baseline and stress-evoked levels of CORT for all rats, without regard to sex, $r(24)=0.41, P<0.05$ (Fig. 3, bottom).

There was also a significant correlation between predator
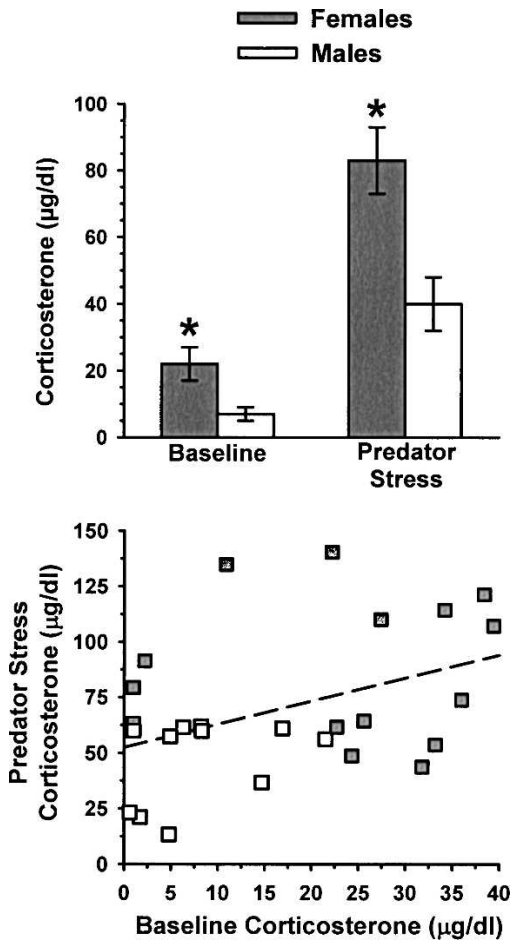

Figure 3. The top graph illustrates serum corticosterone levels in male and female rats trained in experiment 1 . Female rats had greater baseline and stress-evoked levels of corticosterone than males. ${ }^{*} P<0.05$ for sex and time. The bottom graph illustrates the significant linear correlation between baseline and acute stress-evoked corticosterone levels for all rats, regardless of sex, $r(24)=0.41, P<0.05$.

stress-evoked levels of CORT and DTC for females alone, $r(13)=-0.56, P=0.05$. Although this correlation was not significant for males alone, $r(9)=-0.19, P>0.05$, analysis of data from males and females combined resulted in a greater correlation coefficient and level of significance than was found for data from either male or female rats alone, $r(24)=-0.64, P<0.001$ (Fig. 4).

\section{Effects of post-training stress on short-term memory (single-day maze training)}

In experiment 2 , a total of 19 male and 16 female rats (8-10 rats/group) were given a single day of training, with either no stress (home cage) or predator stress occurring during the 30-min period between the acquisition and memory test phases (see

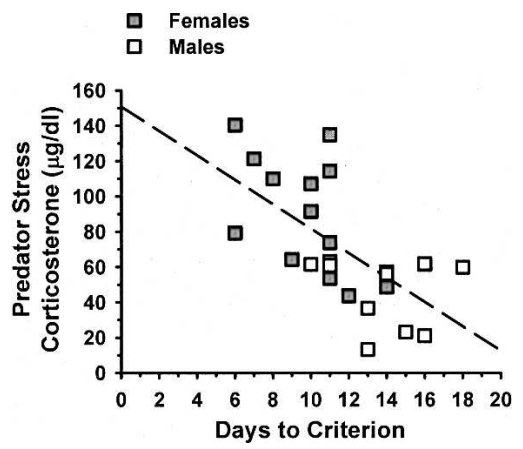

Figure 4. Correlation between the number of days for the rats to reach the performance criterion (DTC) and their later acute corticosterone response to cat exposure. Increased DTC indicates a slower rate at which rats performed the daily memory task. 
timeline for experiment 2, Fig. 1). Analysis of arm entry errors committed during acquisition revealed a significant effect of trials $\left(F_{(11,341)}=20.1, P<0.001\right)$, indicating that the rats made fewer arm entry errors over the course of training (Fig. 5). There were no other significant effects or interactions ( $P$ s $>0.05)$.

Analysis of arm entry errors committed on the 30-min memory test revealed a significant effect of stress $\left(F_{(1,30)}=14.5\right.$, $P<0.001)$, indicating that the stressed group made significantly more arm entry errors than the non-stressed group. There was no significant effect of sex or sex $\times$ trial interaction $(P>0.05)$. These findings demonstrate that predator stress occurring during the 30-min phase between the learning and memory test phases in water maze naïve rats produced a significant and equivalent impairment of memory performance in males and females.

\section{Effects of pretraining stress on short- and long-term memory}

In experiment 3, 16 male and 32 female rats (8-20 rats/group) were given predator stress immediately before the acquisition phase (see timeline for experiment 3, Fig. 1). Analysis of arm entry errors committed during the acquisition phase revealed a significant effect of trials $\left(F_{(17,748)}=12.1, P<0.001\right)$ (Fig. 6). There was also a significant effect of stress $\left(F_{(1,44)}=4.10\right.$, $P<0.05)$, indicating that the stressed groups made more arm entry errors during acquisition than the non-stressed groups. There was also a significant effect of $\operatorname{sex}\left(F_{(1,44)}=6.93, P<0.05\right)$, indicating that the female rats made more arm entry errors during acquisition than the male rats.

Analysis of arm entry errors committed on the 24-h memory test trial revealed a significant effect of stress $\left(F_{(1,42)}=23.5\right.$, $P<0.001)$, indicating that the stressed groups made more arm entry errors than the non-stressed groups (Fig. 6). There was also a significant effect of $\operatorname{sex}\left(F_{(1,42)}=5.51, P<0.05\right)$, indicating that male rats made more arm entry errors than female rats. This effect was primarily driven by a significant stress $\times$ sex interac-

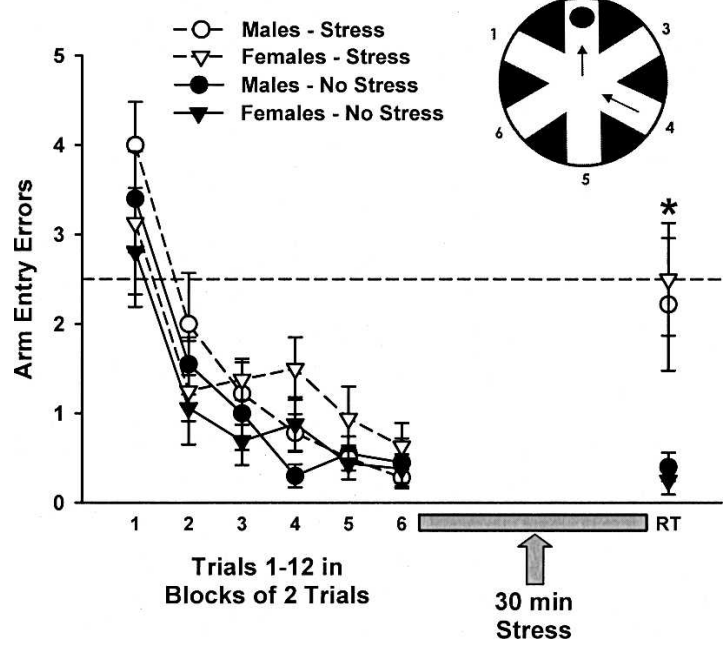

Figure 5. The effects of stress on short-term (30-min) memory in male and female rats (experiment 2). Cat exposure during the 30-min delay period between training and retrieval (indicated by the shaded gray bar) impaired memory in both sexes. The data are presented as mean number of arm entry errors ( \pm SEM) made during acquisition (two-trial blocks) and on the retention trial (RT). The dashed line at 2.5 errors indicates chance level of performance. ${ }^{*} P<0.05$ compared with unstressed male and female controls (Holm-Sidak post-hoc comparisons). A diagram of the RAWM inserted in the upper right corner illustrates swim areas (in white) and the path a rat would take from a start arm (\#4) to the hidden platform in the goal arm (\#2).

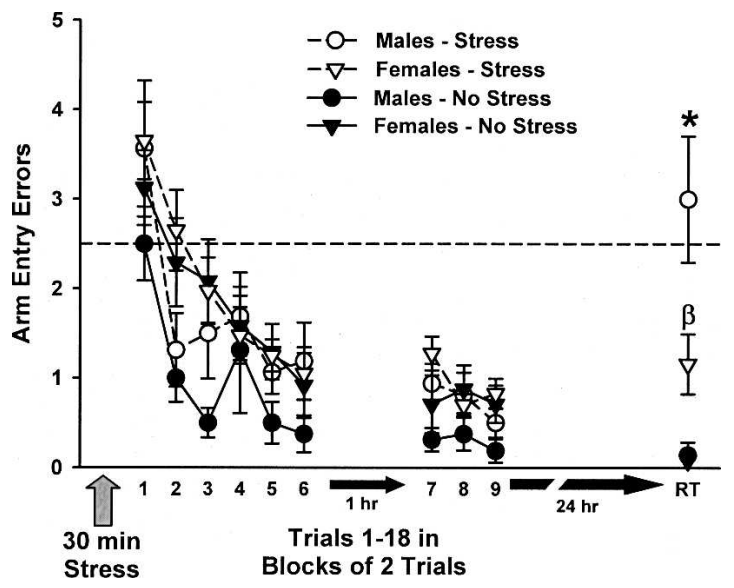

Figure 6. The effects of pretraining stress on long-term (24-h) spatial memory in male and female rats (experiment 3 ). Thirty minutes of cat exposure immediately prior to training impaired memory in both sexes, but female rats demonstrated a milder impairment of 24-h memory. The data are presented as mean number of arm entry errors ( \pm SEM) made during acquisition (two-trial blocks) and on the 24-h retention trial (RT). The dashed line at 2.5 errors indicates chance level of performance. $* P<0.05$ compared with stressed females and unstressed male and female controls; $\beta=P<0.05$ compared with stressed males and unstressed male and female controls (Holm-Sidak post-hoc comparisons).

tion $\left(F_{(1,42)}=5.51, P<0.05\right)$. Although both stressed male and stressed female rats made more arm entry errors than did the non-stressed controls, the stressed male rats made more arm entry errors than did the stressed female rats (all $P \mathrm{~s}<0.05$ ).

\section{Effects of preretrieval stress on long-term (24-h) memory}

In experiment 4, 15 male (seven and eight rats/group) and 30 (12 and 18 rats/group) female rats were given predator stress immediately before the long-term (24-h) memory retrieval trial (see timeline for experiment 4, Fig. 1). Analysis of arm entry errors committed during acquisition revealed a significant effect of trials $\left(F_{(17,1020)}=19.4, P<0.001\right)$, indicating that the rats made fewer arm entry errors as the trials progressed. There were no significant effects of stress or sex (all $P$ s $>0.05$ ), but the sex $\times$ trials interaction was significant $\left(F_{(17,1020)}=3.16\right.$, $P<0.001)$. Post-hoc tests revealed that female rats made more arm entry errors than did male rats on blocks 4 and 5 (trials 7-10; $P<0.05$ ).

Analysis of arm entry errors committed on the 24-h memory test trial revealed a significant effect of stress $\left(F_{(1,57)}=14.46\right.$, $P<0.001)$, indicating that the stressed groups made significantly more arm entry errors than the non-stressed groups (Fig. 7). There was no significant effect of sex, and the stress $\times$ sex interaction was not significant (all $P s>0.05$ ). Therefore, experiment 4 demonstrated that stress occurring before the 24 -h retrieval test produced an equivalent impairment of memory performance in male and female rats.

\section{Discussion}

The primary finding of these experiments is that acute psychological stress (cat exposure) impaired spatial memory in male and female rats trained in the RAWM. This work replicates our previous findings of acute stress-induced memory impairments in male rats (Diamond et al. 1996, 1999, 2006; Woodson et al. 2003; Sandi et al. 2005; Park et al. 2006) and extends these findings to females. Specifically, we have found here that predator stress impaired water maze performance in male and female rats when the stress occurred between the training and 30-min memory test 


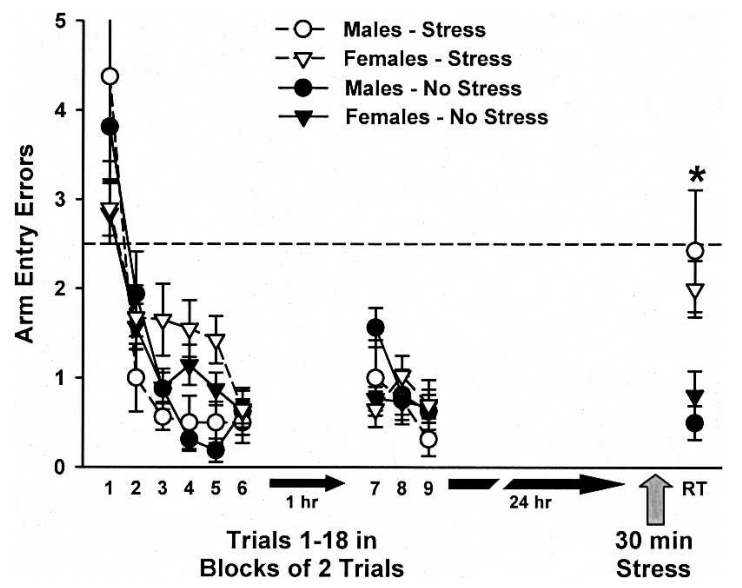

Figure 7. The effects of stress on the retrieval of long-term (24-h) spatial memory in male and female rats (experiment 4 ). Thirty minutes of cat exposure immediately prior to the $24-\mathrm{h}$ retrieval test trial resulted in impaired memory in both sexes. The data are presented as mean number of arm entry errors ( \pm SEM) made during acquisition (two-trial blocks) and on the retention trial (RT). The dashed line at 2.5 errors indicates chance level of performance. ${ }^{\star} P<0.05$ compared with stressed females and unstressed male and female controls (Holm-Sidak post-hoc comparisons).

(experiments 1 and 2), and impaired performance on the 24-h memory test when the stress occurred either before the learning phase (experiment 3 ) or before the 24 -h retrieval trial (experiment 4).

There were three primary differences in how water maze training and predator exposure affected males and females. First, both baseline and stress-evoked levels of CORT were greater in females than in males (Fig. 3). Second, in the multi-day form of training (experiment 1), females were more efficient at reaching the memory performance criterion than males. That is, whereas females achieved a high level of within-day memory performance in $\sim 10 \mathrm{~d}$ of training, males required $\sim 14 \mathrm{~d}$ to reach the same level of performance (Fig. 2). Third, although pretraining stress impaired 24-h memory in both males and females, stress effects on the consolidation of long-term memory were not as profound in the females as they were in the males (Fig. 6). It is known that pretraining stress can influence a subset of rats to shift from a spatial to a nonspatial learning strategy (Kim et al. 2001, 2005; Kim and Diamond 2002). It is possible, therefore, that the stressed females had a greater tendency than the males to shift to a nonspatial (cue-based) learning strategy after predator exposure (Hyde et al. 2000, 2002; Stavnezer et al. 2002; Chen et al. 2004). This putative shift in learning strategy by the stressed female rats could have enabled them to exhibit less impaired 24-h memory performance than the stressed male rats.

Overall, the differences between the males and females were overshadowed by the similarities in how stress affected their CORT and memory. The male and female rats, analyzed together as a single group, exhibited significant correlations involving memory accuracy across days (DTC) and baseline and stressevoked levels of CORT (Figs. 3, 4). Our most important finding is that cat exposure produced strong and largely equivalent adverse effects on the consolidation and retrieval phases of spatial memory in male and female rats (Figs. 2, 5, 6, 7).

\section{Stress effects on memory in relation to theories on stress and hippocampal functioning}

We have hypothesized that a stressful experience induces an endogenous form of synaptic plasticity that "overwrites" recently stored memories of events that were unrelated to the stress experience (Diamond et al. 1999, 2004b, 2005, 2007). In theory, the processing of information with great survival value, such as predator exposure, takes priority over the consolidation and/or retrieval of other (less important) memories out of the predator exposure context, such as the location of a hidden platform in the water maze (de Kloet et al. 1999; Joels et al. 2006; Sandi and Pinelo-Nava 2007). We have proposed that when a rat is exposed to a cat, the rat forms a powerful memory of the predator context as a result of intense and rapid activation of endogenous plasticity in the hippocampus and amygdala (Diamond et al. 2007). This process is of great survival value because it enables a rat to have a strong memory of the predator exposure experience. However, a negative feature of the enhanced processing of the predator context is that processes involved in the consolidation and retrieval of information unrelated to the predator experience, such as the location of the hidden platform, may be impaired.

Our earlier hypothesizing was based entirely on work conducted on male rats. In one example, we showed that male rats exposed to a shock exhibited impaired memory for the platform location in water maze, and intact memory for the place where the shock occurred (Diamond et al. 2004b). In theory, the male rats formed a strong memory for the context in which the shock occurred, but at the same time, the shock caused them to forget the location of the hidden platform. More recently, we reported that male rats exhibited conditioned fear to the context associated with cat exposure (Halonen et al. 2006), which is consistent with the findings from Hubbard et al. (2004), who showed that male and female rats exhibited a strong memory for the place that contained the scent of a cat. These findings indicate that male and female rats generate a strong memory of a cat exposure experience, which, as we have shown in other studies, also produces an impairment of memory for information acquired outside of the cat exposure context (Diamond et al. 2004a; for reviews, see Diamond et al. 2004b, 2005, 2007).

The current findings are consistent with the hypothesis that the hippocampus of female rats, as with males, gives priority to forming memories of the predator experience. In theory, this greater emphasis on the processing of the traumatic (predator exposure) experience interferes with the processing of information that occurred outside of the predator context, such as the location of the hidden platform. Further support for this hypothesis would be the finding that exposing water maze-trained female rats to a cat produces a strong memory of the cat context, while simultaneously impairing their memory of the location of the hidden platform in the water maze.

\section{Correlations between CORT and behavior}

In experiment 1 , we obtained blood samples from rats in response to predator stress (following cat exposure and the memory test trial) and, then 1 wk later, under a baseline (home cage) condition. These two blood samples, obtained at widely separated time points, provided an opportunity to identify correlations and sex differences in CORT and behavior under basal versus stress states.

We found that female rats exhibited significantly greater baseline and stress-evoked levels of CORT than male rats. This observation is consistent with findings from numerous other studies that have shown greater glucocorticoid reactivity by female, compared with male, rodents (Weinstock et al. 1998; Bowman et al. 2006; Louvart et al. 2006). There appear to be species differences in stressor reactivity, however, in that men tend to exhibit greater glucocorticoid responses to stress than women (for a comprehensive review, see Kudielka and Kirschbaum 2005). However, an extensive meta-analysis reported an absence of gender differences in cortisol reactivity (Dickerson and Ke- 
meny 2004). The inconsistent findings on sex differences in cortisol reactivity in people may be based, in part, on the nature of the stressor (Stroud et al. 2002; Schoofs et al. 2008).

We also found a positive within-subject correlation between baseline and stress levels of CORT; rats with higher baseline CORT exhibited greater stress-evoked increases in CORT levels. As these two samples were obtained 1 wk apart, this observation appears to document stable state-trait features of individual rats. That is, there was a consistent relation between a rat's basal emotional state and how it had responded to predator stress on the final day of water maze training. We are not aware if this issue has been addressed in other rodent work, but there is evidence of correlations in people regarding personality variables and stressor reactivity (Pruessner et al. 1997), as well as the presence of a long-lasting, within-subject correlations between basal cortisol levels and the dexamethasone-induced suppression of cortisol (Huizenga et al. 1998).

It is also important to note that the correlation we observed between basal and stress-evoked levels of CORT was sex independent. Despite the fact that, as a group, females had greater CORT levels than males, the overall linear correlation between basal and stress levels of CORT was significant without regard for the sex of the subject. Thus, a connection between basal excitability and acute stress reactivity appears to a sex-independent feature of the hypothalamic-pituitary-adrenal axis.

Finally, we also found a significant correlation between the rate at which rats reached the daily training performance criterion and their acute stress response to cat exposure. That is, in experiment 1 rats were trained to learn, and then remember for $30 \mathrm{~min}$, a new platform location on each day of training. The more efficiently the rats performed the within-day memory component of the task, the more rapidly they could meet the performance criterion that they commit no more than one error on the memory test trial on three consecutive days of training (for more details, see experiment 1 methods). The third consecutive day of highly efficient memory performance was designated the DTC. As a group, female rats required an average of 3.5 fewer days of training to reach their DTC than males (Fig. 2). On an individual basis, however, the rats were heterogeneous in their daily performance, ranging from 6 to $18 \mathrm{~d}$ of training before all rats reached their DTC. In the analysis of all rats, without regard for sex, there was a significant negative correlation between DTC and acute stress-evoked CORT levels. This sex-independent correlation between DTC and stress CORT levels indicates that the more rapidly rats had originally learned the task (less DTC), the more strongly they responded to the cat (greater CORT levels). These findings are potentially relevant to work by Nater et al. (2007), who demonstrated that people who exhibited a stronger cortisol response to psychological stress exhibited better performance on a declarative memory task than those who exhibited a weak cortisol response to stress.

\section{Stress effects on memory in relation to psychopathology in males and females}

Intense psychological stress can have profound effects on physical and mental health, and in some instances, leads to the development of psychopathology, such as PTSD. This disorder affects a subset of traumatized individuals who exhibit symptoms of persistent anxiety, exaggerated startle, and cognitive impairments. Of paramount importance is the finding that these individuals suffer chronic psychological distress, in part, because they continually relive their trauma with intrusive memories. Although women exhibit a greater prevalence of stress-related forms of psychopathology than men (Breslau et al. 1997; Foa and Street 2001; Fullerton et al. 2001; Penza et al. 2003; Nemeroff et al. 2006), both men and women tend to form strong memories of traumatic experiences that may haunt them long after the termination of the traumatic experience. The present findings indicate that an intense, fear-provoking situation produces qualitatively similar deleterious effects on memory in male and female rats. These findings support the notion that memory processing by both sexes is strongly affected in a qualitatively similar manner by traumatic experiences in people (McNally et al. 2006) and rodents (Mazor et al. 2007), and, further, are consistent with indications that PTSD susceptibility in people under extreme trauma conditions is similar in men and women (Kessler 2000; Pole et al. 2001; Galea et al. 2002; Kang et al. 2005; Nemeroff et al. 2006). Therefore, the study of the effects of predator stress on memory may provide insight into sex-independent effects of trauma on human pathological memory processing.

\section{Summary, conclusions, and caveats}

The present experiments revealed that acute predator stress impaired spatial memory consolidation and retrieval at both shortand long-term delays in male and female rats. With the exception of a milder spatial memory impairment as a result of pretraining stress in females, the present studies demonstrated that cat exposure produced a largely equivalent adverse effect on spatial memory in male and female rats. The only substantial sex differences we found were that females required fewer days of training than the males to exhibit consistently accurate withinday memory (experiment 1) and that females had greater baseline and stress-evoked levels of CORT than males.

One strength of this study was that the methodology was conservative in minimizing extraneous factors that could have produced sex-specific influences on the predator stress and water maze findings. For example, we were careful to house and train males and females in isolation from each other, as our pilot work indicated that males housed with females performed more poorly in the water maze than males in single sex housing (data not shown). In addition, we gave males and females identical daily handling conditions, which meant that the females were not subjected to estrus testing. Estrus testing (vaginal swabbing and penetration) is a relatively brief manipulation but has been shown to evoke a profound and long-lasting (60-min) autonomic response in rats (Sharp et al. 2002). Estrus testing, therefore, is a form of sex-specific stress that could have influenced water maze performance and acute predator stress responsivity only in the female rats. Therefore, as this was the first comparative study investigating the effects of extra-maze stress on short- and longterm spatial memory in male and female rats, we were cautious in minimizing any housing or handling stress factors that might have influenced the outcome of the experiment. Whether factors such as mixed sex housing and estrus testing can be shown to influence predator stress responsivity and/or spatial memory remains to be determined.

In summary, we have found that females exhibited water maze learning and memory performance that was equivalent (experiments 2-4) or superior (experiment 1) to that of the males, depending on training methodology. We also found significant sex-independent correlations between stress-evoked levels of CORT and the efficiency at which rats learned the task, and most importantly, the predator stress-induced impairment of hippocampus-dependent memory was largely equivalent in female and male rats.

\section{Materials and Methods}

\section{Subjects}

The subjects were male and female Sprague-Dawley rats ( 2 mo of age; Charles River Laboratories) that were same-sex housed on a 
12-h/12-h light/dark schedule (lights on at $0700 \mathrm{~h}$ ) in Plexiglas cages (two per cage) with food and water provided ad libitum. Colony room temperature and humidity were maintained, respectively, at $20 \pm 1{ }^{\circ} \mathrm{C}$ and $60 \pm 3 \%$. The Institutional Animal Care and Use Committee at the University of South Florida approved all procedures, and care was taken in all experiments to minimize discomfort to the animals.

All rats were given $1 \mathrm{wk}$ to acclimate to the housing environment before the experimental manipulations took place. The rats were transported to the laboratory's water maze training room and handled for 2-3 min each per day during each of the last $3 \mathrm{~d}$ of the 1 -wk acclimation period. Behavioral manipulations were conducted between 0800 and $1400 \mathrm{~h}$.

Males and females were segregated from each other in every phase of the experiment. Thus, all training and stress testing were completed in their entirety for the males first, followed by all training and stress testing for the female rats. The basis for this segregation of the males and females was from a pilot study we conducted, which indicated that males exposed to females performed more poorly and with greater variability in the water maze than did males unexposed to females (data not shown).

\section{Stress manipulation}

To induce predator stress, rats were first placed in small Plexiglas boxes $(28 \times 9 \times 14 \mathrm{~cm})$, with multiple air holes in the top. The rats within the boxes were then placed in a large chamber $(57 \times 57 \times 76 \mathrm{~cm})$, which contained an adult female cat, for 30 min. The Plexiglas box prevented any physical contact between the cat and rats but enabled the rats to be exposed to all other sensory stimuli, such as the sight, smell, and sounds produced by the cat. Moist cat food was smeared on top of the Plexiglas box, which kept the cat's attention directed toward the rats as it ate the food.

\section{Apparatus and water maze training procedures}

The RAWM paradigm has been described at length in previous publications (Diamond et al. 1999, 2006; Woodson et al. 2003; Sandi et al. 2005; Park et al. 2006; Zoladz et al. 2006). Briefly, the RAWM consists of a black, galvanized round tank (168-cm diameter, 56-cm height, $43-\mathrm{cm}$ depth) filled with water $\left(22^{\circ} \mathrm{C}\right)$. Six $\mathrm{V}$-shaped stainless steel inserts $(54-\mathrm{cm}$ height, 56- $\mathrm{cm}$ length) placed in the tank produced six swim arms that radiated from an open central area (see RAWM diagram in Fig. 5, inset). A black, plastic platform (12-cm diameter) was located $1 \mathrm{~cm}$ below the surface of the water at the end of one arm (referred to as the "goal arm"). At the start of each trial, rats were released into one arm (referred to as the "start arm") facing the center of the maze. If a rat did not locate the hidden platform within $1 \mathrm{~min}$, it was guided to the platform by the experimenter. Once a rat found or was guided to the platform, it was left there undisturbed for $15 \mathrm{sec}$.

An arm entry was operationally defined as the rat passing at least halfway down the arm. For each trial, the experimenter recorded the number of arm entry errors and latency for the rat to find the platform. An arm entry error typically consisted of either an entry by the rat into one of the arms that did not contain the hidden platform or, very rarely, an entry by the rat into the goal arm, but it failed to climb on the platform.

In experiment 1 , rats were trained to learn, and then remember, a new location of the hidden platform on each of the many preliminary days of training, as described previously (Diamond et al. 1999; Woodson et al. 2003; Park et al. 2006). In experiments 2,3 , and 4, all learning and memory testing was conducted on a total of either 1 or $2 \mathrm{~d}$ of training and memory testing, as described in recent publications (Sandi et al. 2005; Diamond et al. 2006). The timing and sequence of events on stress-memory training days are illustrated in Figure 1.

\section{Experiment 1: Effects of post-training stress on memory (multi-day training)}

The methods in the multi-day form of water maze training were originally described by Diamond et al. (1999) and then modified to its current form by Woodson et al. (2003) and Park et al. (2006). On each day of training, rats were given four acquisition trials to learn the location of the goal arm (for that day), followed 30 min later by the memory test trial (Fig. 1). Rats were given a maximum search time of 1 min per trial, after which they were allowed to remain on the platform for $15 \mathrm{sec}$. The platform was always in the same arm on each trial within each day and in a different arm across days. The rats, therefore, needed to learn a new goal arm location on each day of training. The start arm was different on each of the five trials.

All rats were run 5-6 d/wk, for up to $3 \mathrm{wk}$, until each rat performed at a high rate of accuracy on the memory test trial on three consecutive days of training. Specifically, rats needed to meet a performance criterion of committing a total of no more than one error on the memory test trial over three consecutive days of training, as we have described previously (Diamond et al. 1999; Woodson et al. 2003; Park et al. 2006). This restrictive criterion ensured that all rats included in this experiment were well-trained and performed at a high degree of accuracy in their within-day spatial learning and memory performance prior to the initiation of stress testing. Therefore, as many as $18 \mathrm{~d}$ of training elapsed before all rats met the criterion.

Once rats met the performance criterion, each was given six more (post-criterion) days of training. The stress manipulation (described above) occurred during each of the six post-criterion days of training. That is, on each of the six post-criterion days of training, rats were given four trials to learn a new platform location, then they were exposed to the cat for $30 \mathrm{~min}$, and then they were given a single memory test trial. In this manner, errors committed during the three criterion days of training provided the within-animal measure of baseline spatial memory performance under non-stress conditions, and errors committed during the $6 \mathrm{~d}$ of post-criterion training provided the measure of stress effects on within-day spatial memory, as described previously (Diamond et al. 1999; Woodson et al. 2003; Park et al. 2006).

\section{Experiment 2: Effects of post-training stress on memory (single-day training)}

In experiment 2, RAWM training was modified to allow for the entire assessment of learning and memory performance, complete with all stress and drug manipulations, in a single day of training. One week after arrival at the university facility, rats were given $3 \mathrm{~d}$ of handling, followed the next day by a single day of water maze testing. All rats were given RAWM training consisting of a single acquisition (learning) session, which was composed of 12 training trials in succession (a maximum of $1 \mathrm{~min} /$ trial). After each trial the rats were allowed to spend $15 \mathrm{sec}$ on the platform. After the 12 th trial, the rats were given a 30 -min period away from the maze during which they were either returned to the home cage (no stress) or given cat exposure (predator stress). For all groups, the 30-min delay period was terminated with a single memory test trial.

\section{Experiment 3: Effects of pretraining stress on memory (24-h testing)}

Experiment 3 assessed the effects of pretraining predator stress on spatial learning, and short-term (1-h) and long-term (24-h) memory in a total of $2 \mathrm{~d}$ of training. Half of the male and female rats were given predator stress for $30 \mathrm{~min}$ immediately prior to training on day 1 , and the other half of the rats remained in their home cages during this time. Day 1 training was composed of 12 massed training trials, followed by a 1 -h period the rats spent in their home cages, which was terminated by six additional training trials. On day 2 , all rats were given a single memory test trial. Rats were not exposed to the cat on day 2.

\section{Experiment 4: Effects of preretrieval stress on memory (24-h testing)}

Experiment 4 tested the effects of predator stress on the retrieval component of long-term (24-h) spatial memory. On day 1 , all 
animals received 12 massed training trials, followed by a 1-h delay period spent in their home cages, which was terminated by six additional training trials. No cat exposure occurred on day 1 . On day 2 , half of the male and female rats remained in their home cages, and the other half of the rats were given predator stress for $30 \mathrm{~min}$ immediately prior to the 24 -h memory test trial.

\section{Blood sampling and CORT assay}

Blood samples were obtained from the rats that were given multiday water maze training (experiment 1). The first blood sample was obtained immediately after the memory trial on the sixth post-criterion day of stress testing; i.e., this was the sixth sequential day in which well-trained rats learned a new location of the platform, followed by $30 \mathrm{~min}$ of cat exposure, followed by a memory test trial. Therefore, the blood sample was obtained after all water maze training was completed. For blood sampling, the rats were placed in a soft wire mesh and then $0.5 \mathrm{~mL}$ of blood was obtained from a small $(1-\mathrm{mm})$ nick in the tip of the tail made by a sterile surgical blade. The entire blood sampling process was completed within 2-3 min after completion of the memory test trial.

A baseline sample of blood from these rats was obtained $\sim 1$ wk later. The sample was obtained at $\sim 0900-1200 \mathrm{~h}$, when rats were removed from the housing room and quickly brought to an adjacent room, where a blood sample was obtained as described above. The entire process (removing a rat from the housing room until the blood sample was obtained) was accomplished within 2 min for each rat. The blood sample was allowed to clot and then it was centrifuged. The serum was collected and stored frozen at $-70^{\circ} \mathrm{C}$ until it was assayed for CORT by radioimmunoassay (RIA).

\section{Statistical analyses}

Separate analyses (SPSS; Sigmastat) were conducted on the acquisition and memory test trial data. The acquisition trials were analyzed with mixed-model ANOVAs, with stress (stress, no stress) and sex (male, female) serving as the between-subjects factors, and trials serving as the within-subjects factor. The memory test trials were analyzed with two-way, between-subjects ANOVAs, with stress and sex serving as the between-subject factors. CORT levels were compared across groups with a mixedmodel ANOVA, with stress (stress, baseline) serving as the withinsubjects factor and sex (male, female) serving as the betweensubjects factor. Pearson product-moment correlations were also performed between the following variables in experiment 1: baseline CORT levels, stress-evoked CORT levels, and water maze performance (DTC and arm entry errors). Holm-Sidak (SPSS, Sigmastat) post-hoc tests were utilized to examine group differences following significant omnibus ANOVAs. Alpha was set at 0.05, and outlier data points greater than 3 SDs from exclusive group means were eliminated from analyses.

\section{Acknowledgments}

This research was supported by a Merit Review Award from the Veterans Administration (D.M.D.) and a grant from NIMH (C.D.C.). We also acknowledge the constructive comments from the anonymous reviewers. Support was received from NIMH no. R01MH064727; VA Merit Review Award.

\section{References}

Adamec, R.E. 2003. Stress effects on limbic function and behavior. Prog. Neuropsychopharmacol. Biol. Psychiatry 27: 1173-1175.

Adamec, R., Kent, P., Anisman, H., Shallow, T., and Merali, Z. 1998. Neural plasticity, neuropeptides and anxiety in

animals-implications for understanding and treating affective disorder following traumatic stress in humans. Neurosci. Biobehav. Rev. 23: 301-318.

Adamec, R., Walling, S., and Burton, P. 2004. Long-lasting, selective, anxiogenic effects of feline predator stress in mice. Physiol. Behav. 83: $401-410$.

Andreano, J.M. and Cahill, L. 2006. Glucocorticoid release and memory consolidation in men and women. Psychol. Sci. 17: 466-470.
Barros, M. and Tomaz, C. 2002. Non-human primate models for investigating fear and anxiety. Neurosci. Biobehav. Rev. 26: 187-201.

Beiko, J., Lander, R., Hampson, E., Boon, F., and Cain, D.P. 2004. Contribution of sex differences in the acute stress response to sex differences in water maze performance in the rat. Behav. Brain Res. 151: $239-253$.

Berntsen, D. and Rubin, D.C. 2006. Flashbulb memories and posttraumatic stress reactions across the life span: Age-related effects of the German occupation of Denmark during World War II. Psychol. Aging 21: 127-139.

Blanchard, R.J., Blanchard, D.C., Agullana, R., and Weiss, S.M. 1991 Twenty-two $\mathrm{kHz}$ alarm cries to presentation of a predator, by laboratory rats living in visible burrow systems. Physiol. Behav. 50: $967-972$.

Blanchard, R.J., Agullana, R., McGee, L., Weiss, S., and Blanchard, D.C. 1992. Sex differences in the incidence and sonographic characteristics of antipredator ultrasonic cries in the laboratory rat (Rattus norvegicus). J. Comp. Psychol. 106: 270-277.

Bower, G.H. and Sivers, H. 1998. Cognitive impact of traumatic events. Dev. Psychopathol. 10: 625-653.

Bowman, R.E., MacLusky, N.J., Diaz, S.E., Zrull, M.C., and Luine, V.N. 2006. Aged rats: Sex differences and responses to chronic stress. Brain Res. 1126: 156-166.

Bremner, J.D. 2003. Long-term effects of childhood abuse on brain and neurobiology. Child Adolesc. Psychiatr. Clin. N. Am. 12: 271-292.

Breslau, N., Davis, G.C., Andreski, P., Peterson, E.L., and Schultz, L.R. 1997. Sex differences in posttraumatic stress disorder. Arch. Gen. Psychiatry 54: 1044-1048.

Cahill, L. 2006. Why sex matters for neuroscience. Nat. Rev. Neurosci. 7: 477-484.

Cahill, L., Gorski, L., Belcher, A., and Huynh, Q. 2004. The influence of sex versus sex-related traits on long-term memory for gist and detail from an emotional story. Conscious. Cogn. 13: 391-400.

Campbell, T., Lin, S., DeVries, C., and Lambert, K. 2003. Coping strategies in male and female rats exposed to multiple stressors. Physiol. Behav. 78: 495-504.

Chen, G.H., Wang, Y.J., Zhang, L.Q., and Zhou, J.N. 2004. Age- and sex-related disturbance in a battery of sensorimotor and cognitive tasks in Kunming mice. Physiol. Behav. 83: 531-541.

Conrad, C.D. 2005. The relationship between acute glucocorticoid levels and hippocampal function depends upon task aversiveness and memory processing stage. Nonlinearity Biol. Toxicol. Med. 3: 57-78.

Conrad, C.D., Jackson, J.L., Wieczorek, L., Baran, S.E., Harman, J.S. Wright, R.L., and Korol, D.L. 2004. Acute stress impairs spatial memory in male but not female rats: Influence of estrous cycle. Pharmacol. Biochem. Behav. 78: 569-579.

de Kloet, E.R., Oitzl, M.S., and Joels, M. 1999. Stress and cognition: Are corticosteroids good or bad guys? Trends Neurosci. 22: 422-426.

de Quervain, D.J., Roozendaal, B., Nitsch, R.M., McGaugh, J.L., and Hock, C. 2000. Acute cortisone administration impairs retrieval of long-term declarative memory in humans. Nat. Neurosci. 3: 313-314.

Diamond, D.M. 2005. Cognitive, endocrine and mechanistic perspectives on non-linear relationships between arousal and brain function. Nonlinearity Biol. Toxicol. Med. 3: 1-7.

Diamond, D.M., Fleshner, M., Ingersoll, N., and Rose, G.M. 1996. Psychological stress impairs spatial working memory: Relevance to electrophysiological studies of hippocampal function. Behav. Neurosci. 110: 661-672.

Diamond, D.M., Park, C.R., Heman, K.L., and Rose, G.M. 1999. Exposing rats to a predator impairs spatial working memory in the radial arm water maze. Hippocampus 9: 542-552.

Diamond, D.M., Campbell, A., Park, C.R., and Vouimba, R.M. 2004a. Preclinical research on stress, memory, and the brain in the development of pharmacotherapy for depression. Eur. Neuropsychopharmacol. (Suppl 5) 14: S491-S495. doi: org/10.1016/j.euroneuro.2004.09.003.

Diamond, D.M., Park, C.R., and Woodson, J.C. 2004b. Stress generates emotional memories and retrograde amnesia by inducing an endogenous form of hippocampal LTP. Hippocampus 14: 281-291.

Diamond, D.M., Park, C.R., Campbell, A.M., and Woodson, J.C. 2005. Competitive interactions between endogenous LTD and LTP in the hippocampus underlie the storage of emotional memories and stress-induced amnesia. Hippocampus 15: 1006-1025.

Diamond, D.M., Campbell, A.M., Park, C.R., Woodson, J.C., Conrad, C.D., Bachstetter, A.D., and Mervis, R.F. 2006. Influence of predator stress on the consolidation versus retrieval of long-term spatial memory and hippocampal spinogenesis. Hippocampus 16: 571-576.

Diamond, D.M., Campbell, A.M., Park, C.R., Halonen, J., and Zoladz, P.R. 2007. The temporal dynamics model of emotional memory processing: A synthesis on the neurobiological basis of stress-induced amnesia, flashbulb and traumatic memories, and the Yerkes-Dodson law. Neural Plast. 60803. doi: 10.1155/2007/60803. 
Dickerson, S.S. and Kemeny, M.E. 2004. Acute stressors and cortisol responses: A theoretical integration and synthesis of laboratory research. Psychol. Bull. 130: 355-391.

Dunmore, E., Clark, D.M., and Ehlers, A. 1999. Cognitive factors involved in the onset and maintenance of posttraumatic stress disorder (PTSD) after physical or sexual assault. Behav. Res. Ther 37: 809-829.

Falconer, E.M. and Galea, L.A. 2003. Sex differences in cell proliferation, cell death and defensive behavior following acute predator odor stress in adult rats. Brain Res. 975: 22-36.

Foa, E.B. and Street, G.P. 2001. Women and traumatic events. J. Clin. Psychiatry (Suppl 17) 62: 29-34.

Fullerton, C.S., Ursano, R.J., Epstein, R.S., Crowley, B., Vance, K., Kao, T.C., Dougall, A., and Baum, A. 2001. Gender differences in posttraumatic stress disorder after motor vehicle accidents. Am. J. Psychiatry 158: $1486-1491$.

Galea, S., Resnick, H., Ahern, J., Gold, J., Bucuvalas, M., Kilpatrick, D., Stuber, J., and Vlahov, D. 2002. Posttraumatic stress disorder in Manhattan, New York City, after the September 11th terrorist attacks. J. Urban Health 79: 340-353.

Gilbertson, M.W., Gurvits, T.V., Lasko, N.B., Orr, S.P., and Pitman, R.K. 2001. Multivariate assessment of explicit memory function in combat veterans with posttraumatic stress disorder. J. Trauma. Stress 14: $413-432$

Halonen, J., Zoladz, P.R., and Diamond, D.M. 2006. Post-training immobilization of rats during predator exposure increases the magnitude and resistance to extinction of conditioned fear. In Proceedings of the Thirty-Sixth Annual Meeting of the Society for Neuroscience. San Diego, CA.

Hebb, D.O. 1955. Drives and the C.N.S. (conceptual nervous system). Psychol. Rev. 62: 243-254.

Hubbard, D.T., Blanchard, D.C., Yang, M., Markham, C.M., Gervacio, A., Chun, I., and Blanchard, R.J. 2004. Development of defensive behavior and conditioning to cat odor in the rat. Physiol. Behav. 80: $525-530$

Huizenga, N.A., Koper, J.W., De Lange, P., Pols, H.A., Stolk, R.P., Grobbee, D.E., De Jong, F.H., and Lamberts, S.W. 1998. Interperson variability but intraperson stability of baseline plasma cortisol concentrations, and its relation to feedback sensitivity of the hypothalamo-pituitary-adrenal axis to a low dose of dexamethasone in elderly individuals. J. Clin. Endocrinol. Metab. 83: 47-54.

Hyde, L.A., Sherman, G.F., and Denenberg, V.H. 2000. Non-spatial water radial-arm maze learning in mice. Brain Res. 863: 151-159.

Hyde, L.A., Stavnezer, A.J., Bimonte, H.A., Sherman, G.F., and Denenberg, V.H. 2002. Spatial and nonspatial Morris maze learning: Impaired behavioral flexibility in mice with ectopias located in the prefrontal cortex. Behav. Brain Res. 133: 247-259.

Jackson, E.D., Payne, J.D., Nadel, L., and Jacobs, W.J. 2005. Stress differentially modulates fear conditioning in healthy men and women. Biol. Psychiatry 59: 516-522

James, W. 1890. Principles of psychology. Holt, New York.

Joels, M., Pu, Z., Wiegert, O., Oitzl, M.S., and Krugers, H.J. 2006. Learning under stress: How does it work? Trends Cogn. Sci. 10: $152-158$.

Kang, H., Dalager, N., Mahan, C., and Ishii, E. 2005. The role of sexual assault on the risk of PTSD among Gulf War veterans. Ann. Epidemiol. 15: 191-195.

Kessler, R.C. 2000. Posttraumatic stress disorder: The burden to the individual and to society. J. Clin. Psychiatry (Suppl 5) 61: 4-12.

Kim, J.J. and Diamond, D.M. 2002. The stressed hippocampus, synaptic plasticity and lost memories. Nat. Rev. Neurosci. 3: 453-462.

Kim, J.J. and Jung, M.W. 2006. Neural circuits and mechanisms involved in Pavlovian fear conditioning: A critical review. Neurosci. Biobehav. Rev. 30: 188-202.

Kim, J.J., Lee, H.J., Han, J.S., and Packard, M.G. 2001. Amygdala is critical for stress-induced modulation of hippocampal long-term potentiation and learning. J. Neurosci. 21: 5222-5228.

Kim, J.J., Koo, J.W., Lee, H.J., and Han, J.S. 2005. Amygdalar inactivation blocks stress-induced impairments in hippocampal long-term potentiation and spatial memory. J. Neurosci. 25: $1532-1539$.

Kirschbaum, C., Wolf, O.T., May, M., Wippich, W., and Hellhammer, D.H. 1996. Stress- and treatment-induced elevations of cortisol levels associated with impaired declarative memory in healthy adults. Life Sci. 58: $1475-1483$.

Korol, D.L. 2004. Role of estrogen in balancing contributions from multiple memory systems. Neurobiol. Learn. Mem. 82: 309-323.

Korol, D.L., Malin, E.L., Borden, K.A., Busby, R.A., and Couper-Leo, J. 2004. Shifts in preferred learning strategy across the estrous cycle in female rats. Horm. Behav. 45: 330-338.

Kudielka, B.M. and Kirschbaum, C. 2005. Sex differences in HPA axis responses to stress: A review. Biol. Psychol. 69: 113-132.
Lanius, R.A., Williamson, P.C., Densmore, M., Boksman, K., Neufeld, R.W., Gati, J.S., and Menon, R.S. 2004. The nature of traumatic memories: A 4-T FMRI functional connectivity analysis. Am. J. Psychiatry 161: $36-44$.

Louvart, H., Maccari, S., Lesage, J., Leonhardt, M., Dickes-Coopman, A., and Darnaudery, M. 2006. Effects of a single footshock followed by situational reminders on HPA axis and behaviour in the aversive context in male and female rats. Psychoneuroendocrinology 31: 92-99.

Lupien, S.J., Buss, C., Schramek, T.E., Maheu, F., and Pruessner, J. 2005. Hormetic influence of glucocorticoids on human memory. Nonlinear Relationships Biol. Toxicol. Med. 3: 23-56.

Mazor, A., Matar, M.A., Kaplan, Z., Kozlovsky, N., Zohar, J., and Cohen, H. 2007. Gender-related qualitative differences in baseline and post-stress anxiety responses are not reflected in the incidence of criterion-based PTSD-like behaviour patterns. World J. Biol. Psychiatry $1-14$.

McFarlane, A.C., Weber, D.L., and Clark, C.R. 1993. Abnormal stimulus processing in posttraumatic stress disorder. Biol. Psychiatry 34: $311-320$.

McGaugh, J.L. 2000. Memory-a century of consolidation. Science 287: $248-251$

McNally, R.J., Perlman, C.A., Ristuccia, C.S., and Clancy, S.A. 2006. Clinical characteristics of adults reporting repressed, recovered, or continuous memories of childhood sexual abuse. J. Consult. Clin. Psychol. 74: 237-242.

Mechiel, K.S. and De Boer, S.F. 2003. A robust animal model of state anxiety: Fear-potentiated behaviour in the elevated plus-maze. Eur. J. Pharmacol. 463: 163-175.

Michael, T., Halligan, S.L., Clark, D.M., and Ehlers, A. 2006. Rumination in posttraumatic stress disorder. Depress Anxiety 24: 307-317.

Nater, U.M., Moor, C., Okere, U., Stallkamp, R., Martin, M., Ehlert, U. and Kliegel, M. 2007. Performance on a declarative memory task is better in high than low cortisol responders to psychosocial stress. Psychoneuroendocrinology 32: 758-763.

Nemeroff, C.B., Bremner, J.D., Foa, E.B., Mayberg, H.S., North, C.S., and Stein, M.B. 2006. Posttraumatic stress disorder: A state-of-the-science review. J. Psychiatr. Res. 40: 1-21.

Ohtani, T., Iwanami, A., Kasai, K., Yamasue, H., Kato, T., Sasaki, T., and Kato, N. 2004. Post-traumatic stress disorder symptoms in victims of Tokyo subway attack: A 5-year follow-up study. Psychiatry Clin. Neurosci. 58: 624-629.

Packard, M.G. 1998. Posttraining estrogen and memory modulation. Horm. Behav. 34: 126-139.

Park, C.R., Campbell, A.M., and Diamond, D.M. 2001. Chronic psychosocial stress impairs learning and memory and increases sensitivity to yohimbine in adult rats. Biol. Psychiatry 50: 994-1004.

Park, C.R., Campbell, A.M., Woodson, J.C., Smith, T.P., Fleshner, M., and Diamond, D.M. 2006. Permissive influence of stress in the expression of a U-shaped relationship between serum corticosterone levels and spatial memory in rats. Dose-Response 4: 55-74.

Penza, K.M., Heim, C., and Nemeroff, C.B. 2003. Neurobiological effects of childhood abuse: Implications for the pathophysiology of depression and anxiety. Arch. Womens Ment. Health 6: 15-22.

Pole, N., Best, S.R., Weiss, D.S., Metzler, T., Liberman, A.M., Fagan, J. and Marmar, C.R. 2001. Effects of gender and ethnicity on duty-related posttraumatic stress symptoms among urban police officers. J. Nerv. Ment. Dis. 189: 442-448.

Pruessner, J.C., Gaab, J., Hellhammer, D.H., Lintz, D., Schommer, N., and Kirschbaum, C. 1997. Increasing correlations between personality traits and cortisol stress responses obtained by data aggregation. Psychoneuroendocrinology 22: 615-625.

Rubin, D.C., Feldman, M.E., and Beckham, J.C. 2004. Reliving, emotions, and fragmentation in the autobiographical memories of veterans diagnosed with PTSD. Appl. Cogn. Psychol. 18: 17-35.

Rubinow, M.J., Arseneau, L.M., Beverly, J.L., and Juraska, J.M. 2004. Effect of the estrous cycle on water maze acquisition depends on the temperature of the water. Behav. Neurosci. 118: 863-868.

Sandi, C. and Pinelo-Nava, M.T. 2007. Stress and memory: Behavioral effects and neurobiological mechanisms. Neural Plast. 2007: 78970.

Sandi, C., Woodson, J.C., Haynes, V.F., Park, C.R., Touyarot, K., Lopez-Fernandez, M.A., Venero, C., and Diamond, D.M. 2005. Acute stress-induced impairment of spatial memory is associated with decreased expression of neural cell adhesion molecule in the hippocampus and prefrontal cortex. Biol. Psychiatry 57: 856-864.

Sauro, M.D., Jorgensen, R.S., and Pedlow, C.T. 2003. Stress, glucocorticoids, and memory: A meta-analytic review. Stress 6: $235-245$.

Schoofs, D., Hartmann, R., and Wolf, O.T. 2008. Neuroendocrine stress responses to an oral academic examination: No strong influence of sex, repeated participation and personality traits. Stress 11: 52-61.

Servatius, R.J. and Shors, T.J. 1994. Exposure to inescapable stress persistently facilitates associative and nonassociative learning in rats. 
Behav. Neurosci. 108: 1101-1106.

Sharp, J.L., Zammit, T.G., and Lawson, D.M. 2002. Stress-like responses to common procedures in rats: Effect of the estrous cycle. Contemp. Top. Lab. Anim. Sci. 41: 15-22.

Shors, T.J. 1998. Stress and sex effects on associative learning: For better or for worse. Neuroscientist 4: 353-364.

Shors, T.J. 2001. Acute stress rapidly and persistently enhances memory formation in the male rat. Neurobiol. Learn. Mem. 75: 10-29.

Shors, T.J. 2005. Estrogen and learning: Strategy over parsimony. Learn. Mem. 12: $84-85$.

Shors, T.J. and Dryver, E. 1992. Stress impedes exploration and the acquisition of spatial information in the eight-arm radial maze. Psychobiology 20: 247-253.

Shors, T.J., Weiss, C., and Thompson, R.F. 1992. Stress-induced facilitation of classical conditioning. Science 257: 537-539.

Stavnezer, A.J., Hyde, L.A., Bimonte, H.A., Armstrong, C.M., and Denenberg, V.H. 2002. Differential learning strategies in spatial and nonspatial versions of the Morris water maze in the C57BL/6J inbred mouse strain. Behav. Brain Res. 133: 261-270.

Stroud, L.R., Salovey, P., and Epel, E.S. 2002. Sex differences in stress responses: Social rejection versus achievement stress. Biol. Psychiatry 52: 318-327.

Weinstock, M., Razin, M., Schorer-Apelbaum, D., Men, D., and McCarty, R. 1998. Gender differences in sympathoadrenal activity in rats at rest and in response to footshock stress. Int. J. Dev. Neurosci. 16: $289-295$

White, N.M. and Salinas, J.A. 2003. Mnemonic functions of dorsal striatum and hippocampus in aversive conditioning. Behav. Brain Res. 142: 99-107.

Wolf, O.T. 2003. HPA axis and memory. Best. Pract. Res. Clin. Endocrinol. Metab. 17: 287-299.

Wolf, O.T., Schommer, N.C., Hellhammer, D.H., McEwen, B.S., and
Kirschbaum, C. 2001. The relationship between stress induced cortisol levels and memory differs between men and women. Psychoneuroendocrinology 26: 711-720.

Wolf, O.T., Kuhlmann, S., Buss, C., Hellhammer, D.H., and Kirschbaum, C. 2004. Cortisol and memory retrieval in humans: Influence of emotional valence. Ann. N. Y. Acad. Sci. 1032: 195-197.

Wood, G.E. and Shors, T.J. 1998. Stress facilitates classical conditioning in males, but impairs classical conditioning in females through activational effects of ovarian hormones. Proc. Natl. Acad. Sci. 95: $4066-4071$.

Wood, G.E., Beylin, A.V., and Shors, T.J. 1998. Hippocampal-dependent trace conditioning is enhanced by stress in males, but impaired by stress in females. Proc. Soc. Neurosci. (Abstract) 24: 682.

Woodson, J.C., Macintosh, D., Fleshner, M., and Diamond, D.M. 2003. Emotion-induced amnesia in rats: Working memory-specific impairment, corticosterone-memory correlation, and fear versus arousal effects on memory. Learn. Mem. 10: 326-336.

Yerkes, R.M. and Dodson, J.D. 1908. The relation of strength of stimulus to rapidity of habit-formation. J Comp Neurol Psychol 18: 459-482

Zoladz, P.R., Campbell, A.M., Park, C.R., Schaefer, D., Danysz, W., and Diamond, D.M. 2006. Enhancement of long-term spatial memory in adult rats by the noncompetitive NMDA receptor antagonists, memantine and neramexane. Pharmacol. Biochem. Behav. 85: 298-306.

Zurkovsky, L., Brown, S.L., Boyd, S.E., Fell, J.A., and Korol, D.L. 2007. Estrogen modulates learning in female rats by acting directly at distinct memory systems. Neuroscience 144: 26-37.

Received August 1, 2007; accepted in revised form January 24, 2008. 


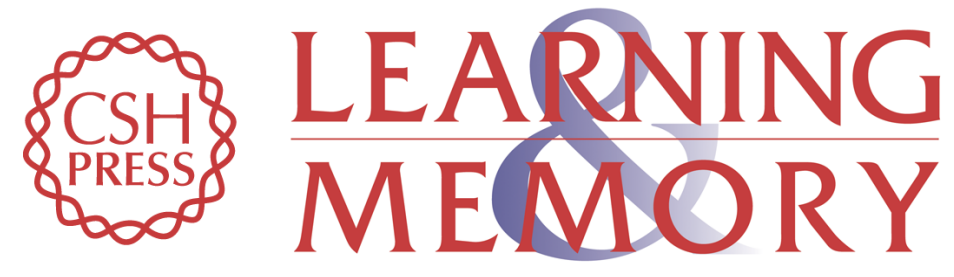

\title{
Acute predator stress impairs the consolidation and retrieval of hippocampus-dependent memory in male and female rats
}

\author{
Collin R. Park, Phillip R. Zoladz, Cheryl D. Conrad, et al.
}

Learn. Mem. 2008, 15:

Access the most recent version at doi:10.1101//m.721108

References This article cites 95 articles, 7 of which can be accessed free at:

http://learnmem.cshlp.org/content/15/4/271.full.html\#ref-list-1

License

Email Alerting Receive free email alerts when new articles cite this article - sign up in the box at the Service top right corner of the article or click here. 